\title{
A retrospective analysis of the pattern of care and survival in patients with malignant ovarian germ cell tumors
}

\author{
Reshu Agarwal, Anupama Rajanbabu, Pavithran Keechilattu', Indu R. Nair², D. K.Vijaykumar ${ }^{3}$, U. G. Unnikrishnan ${ }^{4}$
}

\begin{abstract}
Objective: The objective of this study is to evaluate the pattern of care and survival outcome in patients with malignant ovarian germ cell tumors (MOGCTs). Materials and Methods: Between January 2004 and August 2017, 50 patients with MOGCT were identified at Amrita Institute of Medical Sciences and 48 included in analyses. Histologic subtypes were as follows: dysgerminoma II; immature teratoma I6; yolk sac tumor 3; and mixed germ cell tumor I8. $3 \mathrm{I}$ (64.6\% patients belonged to Stage I and $I 7$ (35.4\%) patients were advanced stage (Stage II-IV). Results: Median follow-up period was 34 months (range: I-24I months). The 5- and I0-year disease-free survival (DFS) and overall survival (OS) for the entire cohort were $87.5 \%$ and $94.4 \%$, respectively. DFS and OS of incomplete surgery Stage I patients $28.6 \%$ and $68.6 \%$, respectively, were significantly lower than completely staged patients $100 \%$. Out of 8 incomplete surgery patients, 5 recurred of which 2 died of disease within 4 and 9 months of recurrence. There was no survival difference with comprehensive surgical staging (CSS) and pediatric surgical staging (PSS) in Stage I MOGCT (DFS and OS 100\%). Stage I dysgerminoma kept on active surveillance after PSS had equivalent survival of $100 \%$. There was no survival difference in advanced stage MOGCT treated with primary debulking surgery and neoadjuvant chemotherapy (NAC) followed by fertility-sparing surgery (DFS and OS 100\%). Conclusion: Incomplete surgery in Stage I MOGCT was associated with poor survival.There was no survival difference with CSS and PSS. NAC followed by surgery could be a reasonable option for patients of advanced stage MOGCT.

Key words:Active surveillance, comprehensive surgical staging, incomplete surgery, malignant ovarian germ cell tumor, neoadjuvant chemotherapy, pediatric surgical staging
\end{abstract}

\section{Introduction}

Malignant ovarian germ cell tumors (MOGCTs) exhibit one of the most extraordinary treatment and prognosis advancement history in the chronicles of gynecological cancers. Before the mid-1960s, virtually all young girls and women either died of disease or cured leaving them infertile with poor quality of life. During this era, treatment available included surgery alone or combined with adjuvant external radiation therapy, radioisotope therapies, or single alkylating agent. ${ }^{[1-3]}$ Over the subsequent five decades, tremendous evolution in surgical and chemotherapeutic approaches made this malignancy curable even with fertility preservation, with the reported 5-year survival rate of $100 \%$ for dysgerminomatous and $85 \%$ for nondysgerminomatous MOGCTs. ${ }^{[4]}$

The current standard treatment regimen includes fertility-sparing surgery (FSS, preservation of the uterus and unaffected ovary) whenever appropriate along with a thorough staging procedure, followed by adjuvant combination chemotherapy with bleomycin, etoposide, and cisplatin (BEP, except for Stage IA pure dysgerminoma and Stage IA Grade 1 immature teratoma). ${ }^{[5]}$

The issues which are still unresolved in the management of MOGCTs include the role of comprehensive surgical staging (CSS); worldwide, till date, there are number of variations in the practice of $\mathrm{CSS}^{[6]}$ extent of completion staging surgery in cases of incompletely staged apparent early stage MOGCT; the role of secondary cytoreductive surgery in patients with recurrent or progressive MOGCTs; ${ }^{[6]}$ the role of surveillance in Stage IA MOGCTs; ${ }^{[6]}$ and the role of neoadjuvant chemotherapy (NAC) in the management of advanced stage MOGCTs. ${ }^{[7,8]}$

The objective of our study was to evaluate the pattern of care and survival outcome in patients with MOGCTs treated at our institute.

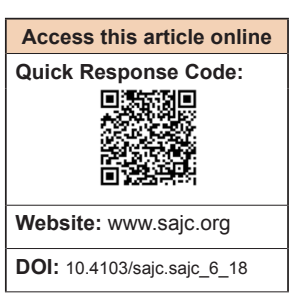

Departments of Gynecologic Oncology, 'Medical Oncology, ${ }^{2}$ Pathology, ${ }^{3}$ Surgical Oncology and ${ }^{4}$ Biostatistics, Amrita Institute of Medical Sciences, Amrita University, Kochi, Kerala, India

Correspondence to: Dr.Anupama Rajanbabu, E-mail:anupamashyam@gmail.com

\section{Materials and Methods}

This is a single-institution retrospective study conducted at Amrita Institute of Medical Sciences (AIMS), Kerala, India. The study was approved by the Institutional Ethical Committee. This included all women who were diagnosed with MOGCT from January 2004 to August 2017. Patients with monodermal teratoma and somatic-type tumors from dermoid cyst (mature cystic teratoma, struma ovarii benign/malignant, carcinoid, neuroectodermal-type tumor, sebaceous tumors, and carcinomas arising in mature cystic teratoma) and mixed germ cell-sex cord-stromal tumor and patients having ovarian cancer other than MOGCT were excluded from the study.

Demographic, clinical, surgicopathological characteristics, details of treatment, recurrence, and survival were collected from electronic medical records and hospital-based cancer registry. Staging in patients undergoing with NAC was based on clinical and radiological information. Histology followed the International Classification of Diseases for Oncology-3.

Patients were subdivided into cohorts based on the stage and treatment received [Figure 1]. Complete surgical staging group was dichotomized into CSS and pediatric surgical staging (PSS). CSS was defined as unilateral salpingo-oophorectomy, omentectomy, peritoneal biopsies, washings, and bilateral pelvic and para-aortic lymphadenectomy. ${ }^{[6]}$ PSS was defined as the visual inspection surgical staging described by Billmire et al., which includes complete resection of tumor-containing ovary with sparing of fallopian tube, inspection and palpation of contralateral ovary, omentum, peritoneal surfaces, and lymph nodes, and collection of peritoneal washings or ascites. ${ }^{[9]}$ Patients kept on

This is an open access journal, and articles are distributed under the terms of the Creative Commons Attribution-NonCommercial-ShareAlike 4.0 License, which allows others to remix, tweak, and build upon the work non-commercially, as long as appropriate credit is given and the new creations are licensed under the identical terms.

For reprints contact: reprints@ medknow.com

How to cite this article: Agarwal R, Rajanbabu A, Keechilattu P, Nair IR, Vijaykumar DK, Unnikrishnan UG. A retrospective analysis of the pattern of care and survival in patients with malignant ovarian germ cell tumors. South Asian J Cancer 2019;8:35-40. 
active surveillance after surgery were evaluated with clinical examination and tumor markers and imaging was done when clinically indicated. Recurrence when suspected was confirmed by imaging. ${ }^{[10]}$

\section{Definition and statistical methods}

Survival analysis was done using Kaplan-Meier method and compared using log-rank test. Disease-free survival (DFS) was defined as the time from diagnosis to date of recurrence, and overall survival (OS) was defined as the time from diagnosis to date of death or last follow-up. Survival after recurrence was defined as the time from relapse to date of death or last follow-up. Categorical variables were expressed as frequency and percentages. $P>0.05$ was considered to be statistically significant. All analysis was performed using IBM SPSS v.20.0 (SPSS Inc, Chicago, USA).

\section{Results}

\section{Patients' characteristics}

Of 874 ovarian malignancies during the study period, 50 (5.7\%) patients had MOGCT of which 48 were included in the study ( 2 patients were excluded due to the lack of treatment details and follow-up).

Clinicopathological and treatment strategies are presented in Table 1. Median age at diagnosis was 20.5 years (range: 8-45 years). Most common presenting symptom was abdominal mass and pain in $85.4 \%$ patients. The most common histologic type was mixed germ cell tumor in $37.5 \%$ of patients. Nearly $64.6 \%$ patients were Stage I at the time of diagnosis.

Twenty-three $(47.9 \%)$ patients received initial treatment elsewhere and were referred to AIMS for subsequent evaluation or for recurrence. Of $38(79.2 \%)$ completely staged patients, $35 / 38(72.9 \%)$ patients underwent FSS.

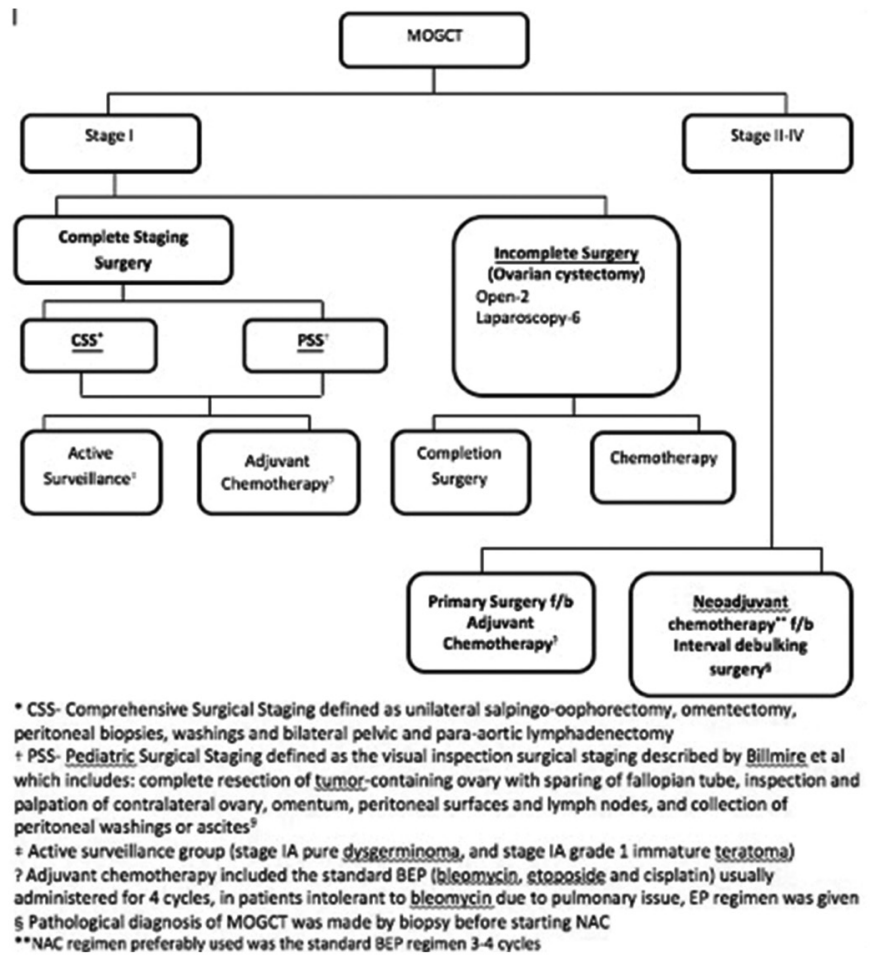

Figure 1: Subdivision of malignant ovarian germ cell tumor patients based on stage and treatment received
Pattern of care in Stage I malignant ovarian germ cell tumor

Of 31 Stage I MOGCT patients, 8 (25.8\%) had dysgerminoma, 13 (41.9\%) had immature teratoma (6 [46.2\%] - Grade 1, $2(15.4 \%)$ - Grade 2, and $5(38.4 \%)$ - Grade 3), 9 (29\%) had mixed germ cell tumor, and $1(3.2 \%)$ had yolk sac tumor (YST). The Federation of Gynecology and Obstetrics (FIGO) stage was IA in $11(35.5 \%)$ and IC in $13(41.9 \%)$, whereas remaining $7(22.6 \%)$ were apparently Stage IA at presentation but upstaged to IC due to intraoperative rupture of tumor and its piecemeal removal [Figure 2].

Surgery represented the first approach to the disease for all the Stage I MOGCT patients; 12 (38.7\%) patients received surgical treatment in AIMS, whereas 19 (61.3\%) were referred in the postoperative setting for subsequent evaluation and/or for recurrence.

Of 23 completely staged patients, 22/23 (95.7\%) patients underwent FSS where all 8 incompletely staged patients underwent FSS in the form of ovarian cystectomy.

Out of 8 incompletely staged patients (all operated outside), only $1(12.5 \%)$ patient received adjuvant chemotherapy, 5 patients presented with recurrence, and 2 patients referred to our center after diagnosis and were offered adjuvant chemotherapy but refused.

\section{Pattern of care in Stage II-IV malignant ovarian germ cell} tumor

Of 17 Stage II-IV MOGCT patients, 3 (17.6\%) had dysgerminoma, $3(17.6 \%)$ had immature teratoma (1 [33.3\%] - Grade 1 and 2 [66.7\%] - Grade 2), $9(52.9 \%)$ had mixed germ cell tumor, and $2(11.8 \%)$ had YST. The FIGO stage was II in $2(11.8 \%)$, III in $12(70.6 \%)$, and IV in $3(17.6 \%)$ patients [Figure 3 ].

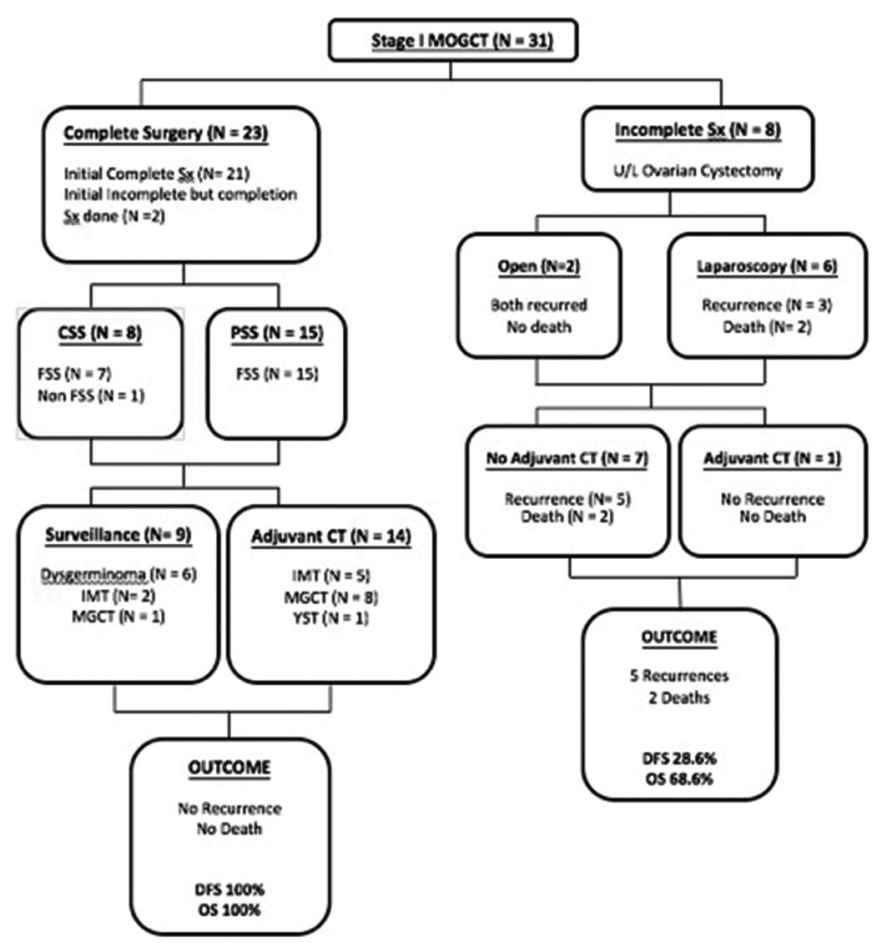

Figure 2: Pattern of care and outcome in Stage I malignant ovarian germ cell tumor

South Asian Journal of Cancer Volume 8 - Issue 1 January-March 2019 
Six $(35.3 \%)$ patients underwent primary debulking surgery (PDS) followed by adjuvant chemotherapy, whereas 11 (64.7\%) patients received NAC followed by interval debulking surgery (IDS). Patients with poor performance status or not suitable for optimal cytoreduction were chosen for NAC. In NAC cohort, 8 (72.7\%) achieved complete pathological response.

In PDS cohort, 4 (66.7\%) patients underwent FSS, whereas in NAC cohort, all $11(100 \%)$ patients underwent FSS.

\section{Outcome}

Median follow-up period was 34 months (range: 1-241 months). Total 5 of $8(62.5 \%)$ incomplete surgery Stage I patients had disease recurrence, with a median time to recurrence of 6 months (range: 3-9 months) [Figures 2-4].

Clinical, treatment, and outcome profile of recurred patients is depicted in Table 2. There was piecemeal removal of cyst and intraoperative spillage of tumor in all. Three out of five patients were wrongly diagnosed as benign mature cystic teratoma initially and presented to our center only on recurrence. Original slides were reviewed and confirmed as immature teratoma. Of these, two died of disease within 4 and 9 months of recurrence.

\section{Full cohort}

DFS was $87.5 \%$ at 5 and 10 years; OS was $94.4 \%$ at 5 and 10 years [Figure $3 \mathrm{a}$ and $\mathrm{b}$ ]. DFS (100\% complete staging

Table 1: Clinicopathological features $(n=48)$

\begin{tabular}{|c|c|}
\hline Variable & $n(\%)$ \\
\hline Age at diagnosis, median (range) & $20.5(9-45)$ \\
\hline Follow-up period, median (range) & $34(1-241)$ \\
\hline \multicolumn{2}{|l|}{ Marital status } \\
\hline Unmarried & $25(52.1)$ \\
\hline Married & $23(47.9)$ \\
\hline \multicolumn{2}{|l|}{ Patients desirous of pregnancy $(n=12)$} \\
\hline Achieved & $10(83.3)$ \\
\hline Not achieved & $2(16.7)$ \\
\hline \multicolumn{2}{|l|}{ Initial presenting symptoms } \\
\hline Abdominal mass and pain & $41(85.4)$ \\
\hline Acute abdominal pain & $3(6.3)$ \\
\hline Incidentally diagnosed & $4(8.3)$ \\
\hline \multicolumn{2}{|l|}{ Type of germ cell tumor } \\
\hline Dysgerminoma $(9060 / 3)$ & $11(22.9)$ \\
\hline Immature teratoma $(9080 / 3)$ & $16(33.3)$ \\
\hline Yolk sac tumor $(9071 / 3)$ & $3(6.3)$ \\
\hline Mixed germ cell tumor $(9085 / 3)$ & $18(37.5)$ \\
\hline \multicolumn{2}{|l|}{ FIGO stage } \\
\hline I & $31(64.6)$ \\
\hline II & $2(4.2)$ \\
\hline III & $12(25)$ \\
\hline IV & $3(6.2)$ \\
\hline \multicolumn{2}{|l|}{ Grade of immature teratoma $(n=16)$} \\
\hline 1 & $7(43.8)$ \\
\hline 2 & $4(25)$ \\
\hline 3 & $5(31.2)$ \\
\hline \multicolumn{2}{|l|}{ Place of first treatment } \\
\hline Amrita & $25(52.1)$ \\
\hline Outside & $23(47.9)$ \\
\hline \multicolumn{2}{|l|}{ Type of first surgery } \\
\hline Complete staging surgery & $38(79.2)$ \\
\hline Fertility-sparing & $35(72.9)$ \\
\hline Nonfertility sparing & $3(6.2)$ \\
\hline Incomplete surgery & $10(20.8)$ \\
\hline
\end{tabular}

vs. $73 \%$ incomplete surgery; $\log$ rank $P=0.011$ ) and OS (100\% complete staging vs. $87.8 \%$ incomplete surgery; log rank $P=0.118$ ) of patients who received complete treatment at our

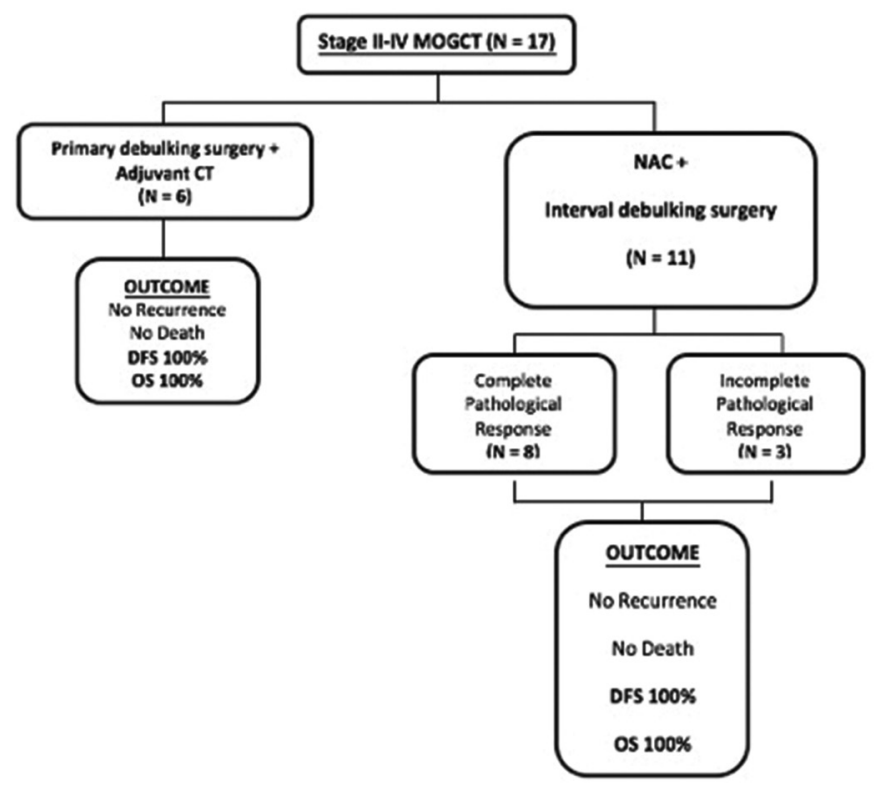

Figure 3: Pattern of care and outcome in advanced Stage (II-IV) malignant ovarian germ cell tumor

Table 2: Clinical, treatment, and outcome profile of malignant ovarian germ cell tumors patients with recurrence $(n=5)$

\begin{tabular}{|c|c|}
\hline Variable & $n(\%)$ \\
\hline Median age of recurred patients (range) in years & $26(15-33)$ \\
\hline Median time of recurrence (range) in months & $6(3-9)$ \\
\hline \multicolumn{2}{|l|}{ Stage } \\
\hline I & $5(100)$ \\
\hline II-IV & 0 \\
\hline \multicolumn{2}{|l|}{ Histologic subtype } \\
\hline Recurrent dysgerminoma & $1(20)$ \\
\hline Recurrent immature teratoma & $4(80)$ \\
\hline Grade 1 & $2 / 4$ \\
\hline Grade 3 & $2 / 4$ \\
\hline \multicolumn{2}{|l|}{ Place of first surgery } \\
\hline Outside & $5(100)$ \\
\hline Amrita & 0 \\
\hline \multicolumn{2}{|l|}{ Type of first surgery } \\
\hline Incomplete (ovarian cystectomy) & $5(100)$ \\
\hline Complete staging surgery & 0 \\
\hline \multicolumn{2}{|l|}{ Mode of first surgery } \\
\hline Open & $2(40)$ \\
\hline Laparoscopic & $3(60)$ \\
\hline \multicolumn{2}{|l|}{ Adjuvant treatment after first surgery } \\
\hline Yes & 0 \\
\hline No & $5(100)$ \\
\hline \multicolumn{2}{|l|}{ Site of recurrence } \\
\hline Abdominal & $5(100)$ \\
\hline Disseminated & $2 / 5(40)$ \\
\hline Localized & $3 / 5(60)$ \\
\hline Extra-abdominal & 0 \\
\hline \multicolumn{2}{|l|}{ Treatment at recurrence } \\
\hline Secondary cytoreductive surgery + chemotherapy & $5(100)$ \\
\hline \multicolumn{2}{|l|}{ Outcome of recurred patients } \\
\hline Alive no disease & $3(60)$ \\
\hline Died of disease & $2(40)$ \\
\hline
\end{tabular}




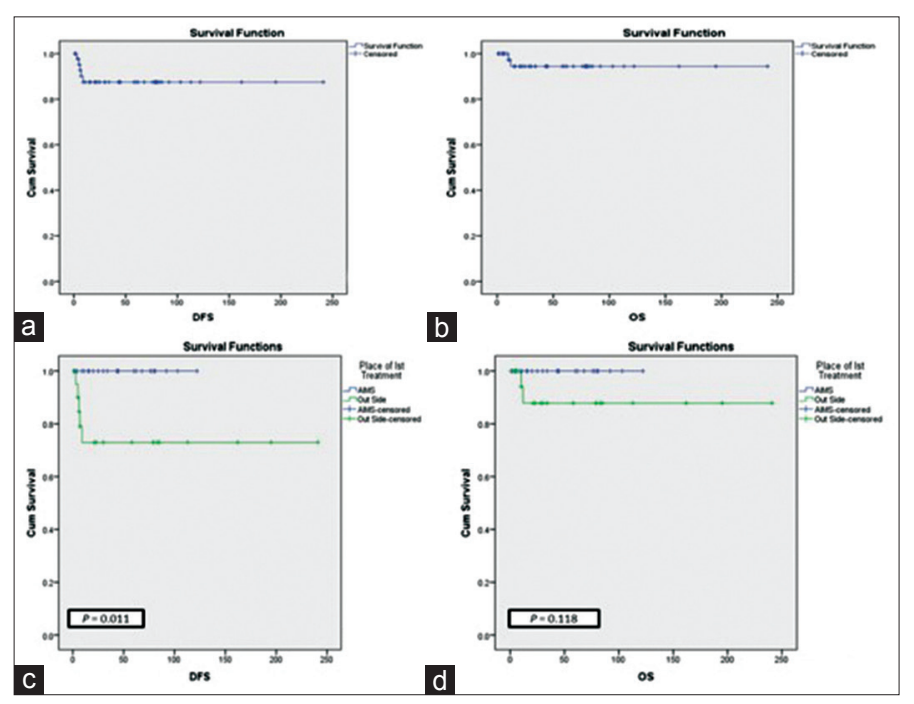

Figure 4: Survival analysis of full cohort (a) disease-free survival of full cohort, (b) overall survival of full cohort, (c) comparative analysis of disease-free survival according to place of treatment, (d) comparative analysis of overall survival according to the place of treatment

institute were significantly higher than patients treated outside and referred [Figure 4].

DFS and OS of Stage I MOGCT patients were $83 \%$ and $90 \%$, respectively [Figure $4 \mathrm{a}$ and b]. DFS (100\% complete surgery vs. $28.6 \%$ incomplete surgery; $\log$ rank $P<0.001)$ and OS $(100 \%$ complete surgery vs. $68.6 \%$ incomplete surgery; $\log$ rank $P=0.027$ ) of complete surgery (primary complete staging + primary incomplete surgery but complete staging surgery done) Stage I MOGCT patients were significantly higher than the incomplete surgery patients [Figure $4 \mathrm{c}$ and d]. CSS and PSS groups had equivalent survival (DFS and OS $100 \%$ in both).

DFS and OS of Stage II-IV MOGCT patients were 100\%. There was no survival difference in the patients with NAC + IDS and PDS group (DFS and OS 100\% in both).

\section{Reproductive outcome}

All 35 (72.9\%) patients who underwent FSS resumed normal menstruation within 1 year of completing treatment. Of the $12(25 \%)$ nulliparous patients desirous of pregnancy, $10 / 12(83.3 \%)$ achieved pregnancy and delivered healthy full-term babies.

\section{Discussion}

Malignant ovarian germ cell tumors (MOGCTs) are rare but aggressive tumors, accounting for only $1 \%-2 \%$ of all ovarian malignancies in the Western world, ${ }^{[1]]}$ but in Asian and black societies, they represent as much as $15 \%{ }^{[12]}$ At our institute, the rate of MOGCT was $5.7 \%$.

MOGCTs principally occur during adolescence and early adulthood. In this study, the median age of diagnosis was 20.5 years which was similar to that (19 years) reported by Talukdar et al..$^{[7]}$ Majority (64.6\%) of patients presented in Stage I, as mentioned in literature. ${ }^{[13]}$

Primary surgical management with FSS is the standard of care for patients with MOGCT (both early and advanced stage) desirous of fertility. The need for CSS in apparent Stage I MOGCT is still debatable. ${ }^{[6]}$ Billmire et al. and Liu et al. showed equivalent survival results in Stage I MOGCT with PSS ${ }^{[9,14]}$ In this study, we found equivalent survival in the
8 patients who underwent CSS and 15 patients who underwent PSS with $100 \%$ DFS and OS at 5 and 10 years. However, in both these studies, all patients received adjuvant chemotherapy irrespective of their histological subtype. In other studies, authors emphasized the need for CSS to identify the occult metastatic (especially lymph node) disease if patients are to be kept on active surveillance. ${ }^{[15-17]}$ They concluded that CSS identified the subset of patients who would unequivocally benefit from adjuvant chemotherapy. Contrary to the evidence in literature, in this study, 33.3\% (5/15) patients with Stage IA dysgerminoma with unilateral salpingo-oophorectomy were kept under surveillance and none of them recurred.

Evidence form large studies suggest that unilateral salpingo-oophorectomy of involved ovary is the standard of care and removal or biopsy of contralateral ovary is not associated with survival benefit. ${ }^{[18-21]}$ The issue of conservative surgery of involved ovary is still unanswered. In our study, 8 patients with Stage I MOGCT who underwent surgery with preservation of involved ovary (cystectomy alone) had significantly higher recurrence rate $(5 / 8)$ and poor OS (2 deaths).

Active surveillance after CSS for Stage IA dysgerminoma and Stage IA Grade 1 immature teratoma is the treatment of choice. ${ }^{[5]}$ Patients with all other stages and histologic types receive adjuvant chemotherapy with standard BEP regimen. The results of pooled analysis of six studies (included 172 patients with Stage IA dysgerminoma, immature teratoma, YST, and mixed tumor) showed relapse rate of $16 \%$ after CSS on active surveillance with OS rate of $98 \% .^{[22-28]}$ Similarly, Billmire et al. showed the relapse rate of $48 \%$ in yolk sac and mixed tumor with 4-year survival rate of $96 \%$ in active surveillance group. ${ }^{[29]}$ These authors recommend active surveillance despite high relapse but good survival rate. On the contrary, Norris et al. reported the relapse rate of $70 \%$ in Grade 3 immature rate with active surveillance and hence strongly recommended adjuvant chemotherapy. ${ }^{[30]}$ Till date, there is no study which has compared the relapse rates and OS rates with CSS and PSS in patients undergoing active surveillance. In our study, $33.3 \%$ patients (5 of 15 patients with PSS) were kept under surveillance after PSS with no relapse rate and OS rate of $100 \%$ at 3 years.

Approximately $60 \%$ patients upstaged to Stage IC due to intraoperative tumor rupture in incomplete surgery cohort experienced disease recurrence. None of them had completion staging surgery and only one patient received adjuvant chemotherapy. One had recurrent dysgerminoma, while other four had recurrent immature teratoma (Grade 1-2 and Grade 3-2) within 3-9 months. They were treated with secondary cytoreductive surgery and chemotherapy. About $40 \%(2 / 5)$ had extensive disease at the time of recurrence and succumbed to death despite of secondary cytoreductive surgery and chemotherapy within 4 and 9 months of recurrence. Contrary to the relapse rate of $30 \%-40 \%$ in literature, the rate of relapse in this study was much higher. Contrary to the fact that YST is the most aggressive tumor with highest relapse, in this study, patients with dysgerminoma and immature teratoma have recurred. This may be attributed to the erroneous initial diagnosis of MOGCT as benign tumor and late detection of recurrences.

South Asian Journal of Cancer • Volume 8 • Issue 1 January-March 2019 
Retrospective reports suggest a possible role for secondary cytoreductive surgery in selected patients with recurrent MOGCT. ${ }^{[31,32]}$ Munkarah et al. reported improved survival only in immature teratoma with secondary surgery. ${ }^{[32]}$ Retrospective studies have proposed that ideal candidates for this surgery would be those with an isolated focus or limited foci of recurrence. Consistent this, we also found that secondary reductive surgery benefitted only patients with limited disease.

In advanced Stage (II-IV) MOGCT, we found equivalent survival with NAC followed by IDS and PDS followed by adjuvant chemotherapy. This study is in complete agreement with the study by Talukdar et al. who reported equivalent reproductive and survival outcome in advanced stage MOGCT in PDS and NAC followed by IDS group. ${ }^{[7]} \mathrm{Lu}$ et al. showed better optimal cytoreduction rate, less perioperative morbidity, and similar DFS in patients with YST who were treated with NAC followed by IDS as compared to those who underwent PDS. ${ }^{[8]}$ Both the authors concluded that NAC could be a reasonable option for patients with advanced stage MOGCT, not suitable for optimal cytoreduction or with poor general condition.

MOGCT has excellent prognosis, with cure rates approaching $100 \%$ for those with early-stage disease and at least $75 \%$ for patients with advanced stage disease. ${ }^{[33]}$ In this study, we found overall DFS of $87.5 \%$ and OS of $94.4 \%$. The cure rate of advanced stage MOGCT was $100 \%$. The cure rate of Stage I MOGCT with complete surgery (CSS/PSS) followed by active surveillance or adjuvant chemotherapy was also 100\%. However, DFS and OS of incompletely staged, Stage I MOGCT patients were significantly poor $28.6 \%$ and $68.6 \%$, respectively.

\section{Conclusions}

Despite the limitation of being a small retrospective single institutional analysis, this study shows the importance of adequate preoperative workup of an ovarian mass in adolescent girls and young women with tumor markers and imaging, preventing spillage in case of minimally invasive surgery, correct pathological diagnosis, and timely referral to oncology unit.

This study also shows the equivalent survival in MOGCTs with CSS and PSS. Patients with Stage IA dysgerminoma may be considered for active surveillance after PSS. Secondary cytoreductive surgery may benefit patients with limited sites of recurrence. NAC may be an option in patients with advanced stage MOGCT with poor performance status and in whom optimal cytoreduction may not be possible.

\section{Financial support and sponsorship}

Nil.

\section{Conflicts of interest}

There are no conflicts of interest.

\section{References}

1. Gershenson DM, Del Junco G, Herson J, Rutledge FN. Endodermal sinus tumor of the ovary: The M. D. Anderson experience. Obstet Gynecol 1983;61:194-202.

2. Gershenson DM, Del Junco G, Copeland LJ, Rutledge FN. Mixed germ cell tumors of the ovary. Obstet Gynecol 1984;64:200-6.

3. Gershenson DM, del Junco G, Silva EG, Copeland LJ, Wharton JT, Rutledge FN. Immature teratoma of the ovary. Obstet Gynecol 1986;68:624-9.

4. Weinberg LE, Lurain JR, Singh DK, Schink JC. Survival and reproductive South Asian Journal of Cancer Volume 8 - Issue 1 • January-March 2019 outcomes in women treated for malignant ovarian germ cell tumors. Gynecol Oncol 2011;121:285-9.

5. National Cancer Comprehensive Network. Ovarian Cancer including fallopian tube cancer and Primary peritoneal cancer (Version 1.2017). LCOH-11 and MS-25. Available from: http://www.nccn.org/ professionals/physician. [Last accessed on $2017 \mathrm{Apr} 12]$.

6. Gershenson DM, Frazier AL. Conundrums in the management of malignant ovarian germ cell tumors: Toward lessening acute morbidity and late effects of treatment. Gynecol Oncol 2016;143:428-32.

7. Talukdar S, Kumar S, Bhatla N, Mathur S, Thulkar S, Kumar L. Neo-adjuvant chemotherapy in the treatment of advanced malignant germ cell tumors of ovary. Gynecol Oncol 2014;132:28-32.

8. Lu Y, Yang J, Cao D, Huang H, Wu M, You Y. Role of neoadjuvant chemotherapy in the management of advanced ovarian yolk sac tumor. Gynecol Oncol 2014; 134:78-83.

9. Billmire D, Vinocur C, Rescorla F, Cushing B, London W, Schlatter M, et al. Outcome and staging evaluation in malignant germ cell tumors of the ovary in children and adolescents: An intergroup study. J Pediatr Surg 2004;39:424-9.

10. National Cancer Comprehensive Network. Ovarian Cancer including fallopian tube cancer and Primary peritoneal cancer (Version 1.2017). LCOH-12. Available from: http://www.nccn.org/professionals/ physician. [Last accessed on 2017 Apr 12].

11. Quirk JT, Natarajan N, Mettlin CJ. Age-specific ovarian cancer incidence rate patterns in the United States. Gynecol Oncol 2005;99:248-50.

12. Low JJ, Ilancheran A, Ng JS. Malignant ovarian germ-cell tumours. Best Pract Res Clin Obstet Gynaecol 2012;26:347-55.

13. Pectasides D, Pectasides E, Kassanos D. Germ cell tumors of the ovary. Cancer Treat Rev 2008;34:427-41.

14. Liu Q, Ding X, Yang J, Cao D, Shen K, Lang J, et al. The significance of comprehensive staging surgery in malignant ovarian germ cell tumors. Gynecol Oncol 2013; 131:551-4.

15. Park JY, Kim DY, Suh DS, Kim JH, Kim YM, Kim YT, et al. Significance of the complete surgical staging of stage I malignant ovarian germ cell tumors. Ann Surg Oncol 2016;23:2982-7.

16. Mangili G, Scarfone G, Gadducci A, Sigismondi C, Ferrandina G, Scibilia G, et al. Is adjuvant chemotherapy indicated in stage I pure immature ovarian teratoma (IT)? A multicentre Italian trial in ovarian cancer (MITO-9). Gynecol Oncol 2010;119:48-52.

17. Lin KY, Bryant S, Miller DS, Kehoe SM, Richardson DL, Lea JS, et al. Malignant ovarian germ cell tumor - Role of surgical staging and gonadal dysgenesis. Gynecol Oncol 2014;134:84-9.

18. Morice P, Denschlag D, Rodolakis A, Reed N, Schneider A, Kesic V, et al. Recommendations of the Fertility Task Force of the European Society of Gynecologic Oncology about the conservative management of ovarian malignant tumors. Int J Gynecol Cancer 2011;21:951-63.

19. Parkinson CA, Hatcher HM, Earl HM, Ajithkumar TV. Multidisciplinary management of malignant ovarian germ cell tumours. Gynecol Oncol 2011;121:625-36.

20. Chan JK, Tewari KS, Waller S, Cheung MK, Shin JY, Osann K, et al. The influence of conservative surgical practices for malignant ovarian germ cell tumors. J Surg Oncol 2008;98:111-6.

21. Weinstein $D$, Polishuk WZ. The role of wedge resection of the ovary as a cause for mechanical sterility. Surg Gynecol Obstet 1975; 141:417-8.

22. Bonazzi C, Peccatori F, Colombo N, Lucchini V, Cantù MG, Mangioni C. Pure ovarian immature teratoma, a unique and curable disease: 10 years' experience of 32 prospectively treated patients. Obstet Gynecol 1994;84:598-604.

23. Dark GG, Bower M, Newlands ES, Paradinas F, Rustin GJ. Surveillance policy for stage I ovarian germ cell tumors. J Clin Oncol 1997; 15:620-4.

24. Cushing B, Giller R, Ablin A, Cohen L, Cullen J, Hawkins E, et al. Surgical resection alone is effective treatment for ovarian immature teratoma in children and adolescents: A report of the pediatric oncology group and the children's cancer group. Am J Obstet Gynecol 1999;181:353-8.

25. Mitchell PL, Al-Nasiri N, A'Hern R, Fisher C, Horwich A, Pinkerton CR, et al. Treatment of nondysgerminomatous ovarian germ cell tumors: An analysis of 69 cases. Cancer 1999;85:2232-44.

26. Patterson DM, Murugaesu N, Holden L, SeckI MJ, Rustin GJ. A review of the close surveillance policy for stage I female germ cell tumors of the ovary and other sites. Int J Gynecol Cancer 2008; 18:43-50.

27. Mann JR, Raafat F, Robinson K, Imeson J, Gornall P, Phillips M, et al. UKCCSG's germ cell tumour (GCT) studies: Improving outcome for children with malignant extracranial non-gonadal tumours-carboplatin, etoposide, and bleomycin are effective and less toxic than previous regimens. J Clin Oncol 2000; 18:3809-18.

28. Baranzelli MC, Bouffet E, Quintana E, Portas M, Thyss A, Patte C. 
Non-seminomatous ovarian germ cell tumours in children. Eur J Cancer 2000;36:376-83.

29. Billmire DF, Cullen JW, Rescorla FJ, Davis M, Schlatter MG, Olson TA. Surveillance after initial surgery for pediatric and adolescent girls with stage I ovarian germ cell tumors: Report from the children's oncology group. J Clin Oncol 2014;32:465-70.

30. Norris HJ, Zirkin HJ, Benson WL. Immature (malignant) teratoma of the ovary: A clinical and pathologic study of 58 cases. Cancer 1976;37:2359-72.
31. Messing MJ, Gershenson DM, Morris M, Burke TW, Kavanagh JJ, Wharton JT, et al. Primary treatment failure in patients with malignant ovarian germ cell neoplasms. Int J Gynecol Cancer 1992;2:295-300.

32. Munkarah A, Gershenson DM, Levenback C, Silva EG, Messing MJ, Morris $M$, et al. Salvage surgery for chemorefractory ovarian germ cell tumors. Gynecol Oncol 1994;55:217-23.

33. Gershenson DM. Management of ovarian germ cell tumors. J Clin Oncol 2007;25:2938-43. 